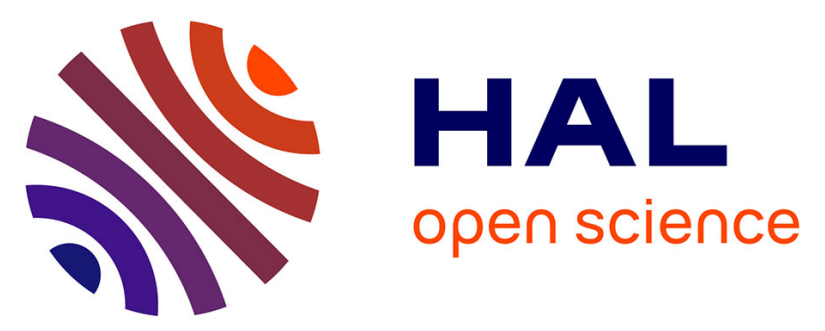

\title{
A new preventive coating for building stones mixing a water repellent and an eco-friendly biocide
}

Stéphanie Eyssautier-Chuine, Ivan Calandra, Nathalie N. Vaillant-Gaveau, Gilles Fronteau, Céline Thomachot-Schneider, Julien Hubert, Jessica Pleck, Maxime Gommeaux

\section{To cite this version:}

Stéphanie Eyssautier-Chuine, Ivan Calandra, Nathalie N. Vaillant-Gaveau, Gilles Fronteau, Céline Thomachot-Schneider, et al.. A new preventive coating for building stones mixing a water repellent and an eco-friendly biocide. Progress in Organic Coatings, 2018, 120, pp.132-142. 10.1016/j.porgcoat.2018.03.022 . hal-02409969

\section{HAL Id: hal-02409969 \\ https://hal.univ-reims.fr/hal-02409969}

Submitted on 6 Nov 2021

HAL is a multi-disciplinary open access archive for the deposit and dissemination of scientific research documents, whether they are published or not. The documents may come from teaching and research institutions in France or abroad, or from public or private research centers.
L'archive ouverte pluridisciplinaire HAL, est destinée au dépôt et à la diffusion de documents scientifiques de niveau recherche, publiés ou non, émanant des établissements d'enseignement et de recherche français ou étrangers, des laboratoires publics ou privés. 


\title{
A NEW PREVENTIVE COATING FOR BUILDING STONES MIXING A WATER REPELLENT AND AN ECO-FRIENDLY BIOCIDE
}

Stéphanie Eyssautier-Chuine ${ }^{\mathrm{a}, *}$, Ivan Calandra ${ }^{\mathrm{b}}$, Nathalie Vaillant-Gaveau ${ }^{\mathrm{c}}$, Gilles Fronteau ${ }^{\mathrm{a}}$, Céline Thomachot-Schneider ${ }^{\mathrm{a}}$, Julien Hubert ${ }^{\mathrm{a}}$, Jessica Pleck ${ }^{\mathrm{d}}$, Maxime Gommeaux ${ }^{\mathrm{a}}$.

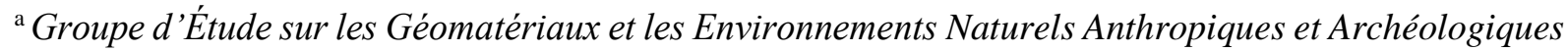
EA 3795 (GEGENAA) - SFR Condorcet FR CNRS 3417 - Université de Reims Champagne-Ardenne, Reims, France.

b TraCEr, MONREPOS Archaeological Research Centre and Museum for Human Behavioural Evolution, RGZM, Neuwied, Germany.

${ }^{\mathrm{c}}$ Unité de Recherche Vignes et Vins de Champagne URVVC EA 4707. Laboratoire de Stress, Défense et Reproduction des Plantes - SFR Condorcet FR CNRS 3417 - Université de Reims ChampagneArdenne, Reims, France.

${ }^{\mathrm{d}}$ Centre de Ressources Technologiques en Chimie (CERTECH), Seneffe, Belgique.

Keywords: coating, biocide, hydrophobic, chitosan, silane/siloxane, Cultural Heritage.

* Corresponding author (S. Eyssautier-Chuine) at: GEGENAA - Université de Reims ChampagneArdenne, CREA, 2 Esplanade R. Garros, 51100 Reims, France. Tel: +33 326773689 Fax : +33 326 773 694. E-mail address: stephanie.eyssautier@univ-reims.fr.

\section{Graphical abstract}

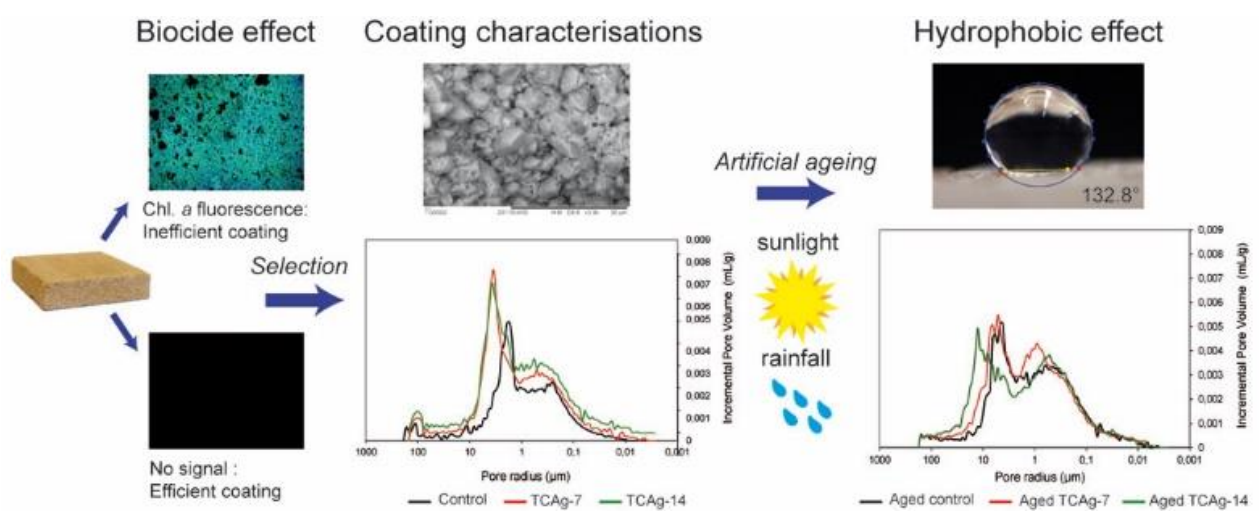

\begin{abstract}
The durability of stone monuments is a constant problem as their decay through weathering is irremediable and endless. Fortunately, coatings are becoming more and more efficient and tailored to specific alterations of the stone material. This study aimed at developing an eco-friendly coating with both hydrophobic and biocide properties based on a silane/siloxane emulsion as a water repellent combined with chitosan and silver nitrate as biocides. Chitosan was first added at different concentrations to the water repellent and its efficacy was tested in laboratory conditions by the inoculation of axenic suspension of the green algae Chlorella vulgaris on a building porous limestone. Chlorophyll $a$ fluorescence analysis displayed the chitosan acted on the photosystem of algae and limited their development but its effect was not optimal and higher dose modified the aspect of the stone. Low concentration of silver nitrate achieved a good performance thanks to the combination with the chitosan and the water repellent. The properties of coated stones and the efficacy of the formulation were assessed at two different doses of coating. The results showed that the lowest dose gathered all requirements to both preserve the stone monument with a weak colour change over time and to reach optimal biocide effect and a good hydrophobicity.
\end{abstract}




\section{Introduction}

For centuries, stone has been considered to be the perfect building material thanks to its durability. It imparted nobility and demonstrated the power and wealth of the building owners. The choice of stones was often dictated more by their aesthetics and availability rather than by their physical and mechanical properties. Now, the historical and cultural significance of many monuments calls to their preservation. The first effects of weathering are aesthetic but eventually lead to disintegration. Preserving stone in Cultural Heritage is a more effective way to assist in conservation than operating on altered stones by consolidation and substitution, processes that are more expensive and difficult since many quarries are now closed.

Weathering is mainly caused by climatic and anthropic conditions modulated by the intrinsic properties of stone linked to the fabric elements [1,2]. Water is the main natural factor of weathering which penetrates inside the stone directly by rainfall or by capillary rise. It causes damage through its chemistry laden with salts or pollutants and its mechanical stress induced by the changing states with temperature variations [3-5]. Protective layers, in the form of natural coatings, have been applied for a long time to prevent stone alteration. Some of them are still under study like oxalate salts for the protection of marble and limestone against chemical weathering [6]. Nevertheless, the development of water repellents based on synthetic inorganic and organic polymers substantially increased their efficiency and durability [7]. Hybrid coatings developed since the 1980s are mixed organic and inorganic components in mild synthetic conditions such as sol-gel process using metallo-organic precursors [8-10]. They have a good hydrophobic function that can still be improved to reach a superhydrophobicity with the silica nanoparticles embedded at various concentrations [11-13]. Avoiding the ingress of water could be the key to stop all the deleterious effects that alter stone monuments, but environmental factors like wall orientation, stone position and shape could favour biological degradation despite the application of a water repellent [14]. The intrinsic properties of building materials such as roughness, porosity and mineral composition also provide an appropriate environment for biological adhesion [15-17], thus compromising the efficiency of water repellents [18]. Furthermore, biocides used to remove biofouling inhibit the efficiency of water repellent if applied later [19]. Nowadays biocides are specifically developed for a preventive effect. Thanks to sol-gel process, many hybrid coatings are easily functionalised by the incorporation of metals as $\mathrm{Ag}, \mathrm{Cu}, \mathrm{Zn}$, widespread for their antimicrobial properties and used in many fields for a long time [20]. In Cultural Heritage, they are still being investigated thanks to the emergence of nanoparticles (NPs - CuNPS, CuONPs, AgNPs, ZnONPs...), whose the performance has been assessed [21-24]. For many years, great interest has been devoted to the photocatalytic activity of the $\mathrm{TiO}_{2}$, but many drawbacks persisted, e.g. its dependence on the wall exposition to sunlight, on the formation of soluble salts, on the dissolution of $\mathrm{TiO}_{2}$ by rainfall and on its superhydrophilicity [25]. The best solution to reduce the penetration of water into the stone whilst keeping a biocide effect seemed to mix a water repellent and a biocidal or self-cleaning coating. Many studies demonstrated the effectiveness and the interaction of different components [13,26-28].

The present study aims at developing a new protective coating combining hydrophobic and biocide effects. Because many biocides have been banned due to their negative impact on the environment and human health, this research looked for an eco-friendly alternative. The chitosan, a polysaccharide derived from the chitin of crustaceans, exhibits an antibacterial activity despite its low toxicity towards mammalian cells $[29,30]$.

In a previous study [31], the biocide effects of coatings based on tetraethoxysilane functionalised with hydrophobic silica as the water repellent were tested through chlorophyll $a$ fluorescence with different $\mathrm{AgNO}_{3}$ concentrations as the biocide. The lowest concentration of $\mathrm{AgNO}_{3}$, when combined with chitosan and hydrophobic silica achieved an optimal biocide impact. Therefore, the addition of chitosan allowed reducing the use of $\mathrm{AgNO}_{3}$, which is environmentally desirable. Moreover, the previous study used hydrophobic silica as the water repellent, which dispersed heterogeneously on the stone. The hydrophobic effect was also improved in the present study by the use of a hybrid silane/siloxane polymer. So the present study aimed at finding the best coating with chitosan as the only biocide or the best mixing of chitosan, silver nitrate and water repellent. It was designed to first validate the biocide effect with a biofouling test in laboratory conditions using the green alga Chlorella vulgaris. In a second step, coatings whose biocide impact was validated were further assessed for their influence on the aspect 
and microstructural properties of the stone. Finally, the hydrophobic performance and the durability were evaluated by artificial ageing procedure simulating sunlight and rainfall.

\section{Material and Methods}

\subsection{Substrate: Dom Stone}

Experiments were performed on a stone used in buildings and monuments in northern France and southern Belgium [32]. It is a limestone called the Dom stone dated from the Bajocian (180 Ma). For this study, fresh stone blocks were collected from the underground quarry located in the Dom-le-Mesnil village of the French Ardennes.

Dom stone is a russet bioclastic stone including iron oxide content $(0.5 \%)$ and made of calcitic debris (85\%): numerous echinoderm ossicles $(25 \%)$ in a syntaxic cement $(35 \%)$, shell fragments $(10 \%)$, micritic grains $(10 \%)$ and with only few quartz grains $(5 \%)$ scattered in the rock [33]. It was chosen for its interesting petrophysical properties. Mercury $(\mathrm{Hg})$ porosity value is about at $21.4 \%$. The poresize distribution is bimodal with a major pore access radius at $1.8 \mu \mathrm{m}$ and a second one at $0.25 \mu \mathrm{m}$. More precisely, $51.6 \%$ of pore access radii are larger than $1 \mu \mathrm{m}, 41 \%$ are between 1 and $0.1 \mu \mathrm{m}$ and $7.4 \%$ are between 0.1 and $0.01 \mu \mathrm{m}$. The capillary coefficient $\mathrm{C}_{1}$ relative to the weight increase per surface and per square root of time unit is $146 \mathrm{~g} \cdot \mathrm{m}^{-2} \cdot \mathrm{s}^{-1 / 2}$ [34] and implies good connectivity in the intergranular macroporosity. Such characteristics make the stone particularly sensitive to weathering like heterogeneous disintegration [35] and mainly favour a bioreceptivity that results in a significant greening of the stone [36].

\subsection{Composition and application of coatings}

The protective coatings presented in this study have as a basis a formulation named Tegosivin ${ }^{\circledR} \mathrm{HE} 328$ developed by Evonik Industries AG. It is an emulsion concentrate based on organo-modified siloxanes and alkoxy-functional silanes. The polymerisation of this material is achieved at room temperature through a sol-gel process. This chemistry involves the evolution of nanoparticles in colloidal solution in a polymer network by gelation using Silicon as a precursor. Tegosivin ${ }^{\circledR}$ HE 328 was designed for the impregnation of building materials such as brick, stone and concrete, and is often used as a protective coating for porous stones in monuments $[37,38]$. It is diluted in water whereas many hybrid nanocomposite materials are diluted in organic solvents that promote the penetration of the treatment $[39,40]$ but are less environmental friendly and pose health problem to the person applying the treatment. Moreover, Tegosivin ${ }^{\circledR}$ HE 328 was used here both as the precursor for the polymerisation of coatings and for its hydrophobic property.

Dom stone blocks were cut in prismatic slabs $(5 \times 5 \times 1 \mathrm{~cm})$ dried at $70^{\circ} \mathrm{C}$ in a forced-air oven. They were weighed every day until the weight was stable. Products were sprayed on stone at a distance of about $20 \mathrm{~cm}$ in a single-step application with an airbrush tool which provides an air pressure of 8 bar and $25 \mathrm{~L} / \mathrm{min}$. Many procedures of coating application were investigated and the spraying procedure was used to match with the use of restoration workers and to limit the loss of product. They were applied on triplicate stone slabs. Table 1 gives an overview of the seven coatings investigated with their respective concentrations, their consumption and dry weight on samples. All tested coatings were based on $97 \mathrm{~g} / \mathrm{L}$ of Tegosivin ${ }^{\circledR} \mathrm{HE} 328$ diluted in distilled water. Two biocide agents, commercially acquired from Sigma-Aldrich, were added. Chitosan is a poly-glucosamine polymer commonly obtained by deacetylating chitin from crustacean waste. It is currently used in the food-processing industry because of its bacteriostatic activity $[30,41]$. Chitosan was dissolved in lactic acid and mixed to the water repellent. It was tested at three different concentrations spanning one order of magnitude (TC-7 samples). Silver nitrate was added in low concentration to chitosan in order to improve the biocidal impact (HY samples). Silver is a component well-known for its antibacterial efficiency and is widely used in many fields (cosmetics, medicine, food industry) and notably against green algae $[23,42,43]$. Silver nitrate was chosen rather than silver nanoparticles (AgNPs). The relative toxicity of $\mathrm{AgNO}_{3}$ and $\mathrm{AgNPs}$ is still being discussed, with studies reporting that $\mathrm{AgNO}_{3}$ is more toxic than AgNPs [44,45], while other studies led to the opposite conclusion [21]. Moreover, $\mathrm{AgNPs}$ could release $\mathrm{Ag}^{+}$in the environment [46] as $\mathrm{AgNO}_{3}$ does. Hence, we consider that both compounds have an equivalent toxicity. 


\begin{tabular}{lllllll}
\hline $\begin{array}{l}\text { Coating } \\
\text { name }\end{array}$ & Test & Function & $\begin{array}{l}\text { Applied product } \\
\text { quantity }\left(\mathrm{L} . \mathrm{m}^{-2}\right)\end{array}$ & $\begin{array}{l}\text { Equivalent } \\
\text { dry weight } \\
\left(\mathrm{g} . \mathrm{m}^{-2}\right)\end{array}$ & $\begin{array}{l}\text { Chitosan } \\
(\mathrm{g} / \mathrm{L})\end{array}$ & $\begin{array}{l}\text { Silver nitrate } \\
(\mathrm{g} / \mathrm{L})\end{array}$ \\
\hline TC-7 & Biofouling & WR + biocide & 0.2 & 7 & 1.5 & \\
TC $^{+}-7$ & Biofouling & WR + biocide & 0.2 & 7 & 10.1 & \\
TC $^{++}-7$ & Biofouling & WR + biocide & 0.2 & 7 & 13.6 & 0.9 \\
TCAg-7 & Ageing + biofouling & WR + biocide & 0.2 & 7 & 1.5 & 0.9 \\
TCAg-14 & Ageing + biofouling & WR + biocide & 0.4 & 14 & 1.5 & \\
T-7 & Ageing & WR & 0.2 & 7 & & \\
T-14 & Ageing & WR & 0.4 & 14 &
\end{tabular}

151

153

154

155

156

157

158

159

160

161

162

163

164

165

166

167

168

169

170

171

172

173

174

175

176

177

178

179

180

181

182

183

184

185

186

187

188

189

190

191

192

193

194

195

Table 1

Coating names with the test used for their efficacy, their function, the applied product quantity, the equivalent dry weight and the concentration of components (Tegosivin ${ }^{\circledR}$ HE 328 concentration is not mentioned as it is $97 \mathrm{~g} / \mathrm{L}$ in all coatings).

\subsection{Experimental design}

\subsubsection{Accelerated biofouling test}

An accelerated biocolonisation test was set up on triplicates of control samples (i.e. uncoated stones) and samples coated with the water repellent and biocides (TC-7 and TCAg samples; Table 1). It consisted of inoculating slabs with a suspension of Chlorella vulgaris culture. Chlorella vulgaris fo. Viridis (Chodat) was purchased from the Culture Collection of Algae and Protozoa (Dunstaffnage Marine Laboratory, Scotland; strain reference CCAP 211/12). Algae were first grown in a liquid culture medium composed of distilled water with BG11 (a medium from Sigma-Aldrich concentrated 50 times). It was diluted to get a similar algal concentration for every test corresponding to $574 \pm 58$ algae cells per $\mathrm{mm}^{3}$, as measured by the chlorophyll $a$ absorbance control at $665 \mathrm{~nm}$ and $653 \mathrm{~nm}$ using spectrophotometry. Stone slabs were placed in Plexiglass cups. The cups were filled to the top with algal suspension, $5 \mathrm{~mm}$ above the stone surface. Gravitational settling of the algae was achieved by letting the slabs stand for 24 hours to obtain a homogeneous seeding. Then the broth was removed and distilled water was added up to $0.5 \mathrm{~cm}$ from the bottom of each sample. Water was added regularly over the entire incubation period to ensure that the stones were continually kept wet by means of capillary absorption. The biofouling test was carried out under neon lights (Sylvania Gro-Lux) for four weeks at room temperature $\left(20^{\circ} \mathrm{C}\right)$. Colour and chlorophyll $a$ fluorescence were measured weekly.

\subsubsection{Artificial ageing test}

The test was performed on triplicates of (1) control slabs as new uncoated stones, (2) slabs coated with Tegosivin ${ }^{\circledR}$ HE 328 (TG samples) and (3) slabs with the coatings that showed the best efficacy during the biofouling test ( HY samples - Table 1). The performance of every coating was tested after one month of artificial ageing with the climatic chamber Suntest XXL+ from Altas. The device is equipped with three $1700 \mathrm{~W}$ air-cooled Xenon Lamps to simulate daylight with measurement and control of irradiance 300-400 nm, chamber temperature (CHT) and black standard (BST). Rain was simulated by spray system with two nozzles (Schlick nozzle $11-90^{\circ}=420 \mathrm{ml} /$ nozzle $/ \mathrm{min}$ ). One cycle lasted 4 hours and consisted of: 2 min of spray and $238 \mathrm{~min}$ of daylight fixed at $50 \mathrm{~W} \cdot \mathrm{m}^{-2}$, with CHT at $40^{\circ} \mathrm{C}$ and BST at $60^{\circ} \mathrm{C}$. The total artificial ageing procedure was 168 cycles corresponding to one month of experiment. According to the information providing by Atlas, based only on sunlight radiation, one month of artificial ageing corresponds to five months of real exposure in southern France. Static contact angles and colour changes were measured after 42, 84, 126 and 168 cycles.

\subsection{Evaluation of coated stone properties and performance}

\subsubsection{Colourimetry}


The colour of stone samples was measured by using a Chroma Meter CR-400 from Konica-Minolta with a light projection tube CR-A33c of $11 \mathrm{~mm}$ diameter (corresponding to the measurement zone). Calibrations were performed with a white ceramic plate CR-A43. Values are given in the CIELAB colour space [47]. Three parameters determine the colour location in colour space: $\mathrm{L}^{*}$ indicates lightness $(0=$ absolute black, $100=$ absolute white $)$, and $\mathrm{a}^{*}$ and $\mathrm{b}^{*}$ are the chromaticity coordinates. $\mathrm{a}^{*}$ is the position between green $\left(a^{*}<0\right)$ and red/magenta $\left(a^{*}>0\right) ; b^{*}$ is the position between blue $\left(b^{*}<0\right)$ and yellow $\left(b^{*}>0\right)$. $h_{a b}$, corresponding to the hue angle, is calculated from the $a^{*}$ and $b^{*}$ parameters: $h_{a b}=$ $\left.\arctan \left(b^{*} / a^{*}\right)\right)$.

For colour analysis, each stone surface was measured 9 times and the mean was calculated for every triplicate. Measurements were taken before and after coating and at every stage of tests (see section 2.3). The CIELAB lightness and chroma differences were calculated: $\Delta \mathrm{L}^{*}, \Delta \mathrm{a}^{*}, \Delta \mathrm{b}^{*}$, and $\Delta \mathrm{h}_{\mathrm{ab}}$ correspond to the differences between different surface conditions. The global colour variation $\left(\Delta \mathrm{E}^{*} \mathrm{ab}\right)$ was calculated as follows:

$\Delta \mathrm{E}_{\mathrm{ab}}^{*}=\sqrt{\Delta \mathrm{L}^{* 2}+\Delta \mathrm{a}^{* 2}+\Delta \mathrm{b}^{* 2}}$

First, colour was measured on the coated stones before testing and compared to the natural stone colour (control). Then, the $\Delta \mathrm{a}^{*}$ parameter was used to follow the greening of stones by Chlorella vulgaris during the accelerated biofouling test. The calculation represents the difference between a* after 24 hours of inoculation of slabs by algae $(T=0)$ and each week for one month of incubation. Finally, colour parameters were used during the artificial ageing test where parameters of colour variation $\left(\Delta \mathrm{E}^{*}{ }_{\mathrm{ab}}, \Delta \mathrm{L}^{*}\right.$, $\left.\Delta \mathrm{h}_{\mathrm{ab}}\right)$ were defined as the difference between colour of coated surface before test $(\mathrm{T}=0)$ and after each test week corresponding to $42,84,126$ and 168 cycles.

\subsubsection{Chlorophyll a fluorescence}

The fluorescence arising from chlorophyll (chl.) is almost exclusively from photosystem II (PSII). The sensitivity of the PSII to the environmental variations reflects a stress that the chl. $a$ fluorescence can detect [48]. The chl. $a$ fluorescence of algae was quantified directly on the stone slabs with an IMAGING-PAM Chlorophyll Fluorometer (Walz, Effeltrich, Germany) after every incubation week during four weeks.

The measuring system uses an array of blue light-emitting diodes (LEDs) (peak wavelength $=470 \mathrm{~nm}$ ) for saturating light pulses. The frequency of the pulses was adjusted to $10 \mathrm{~Hz}$. Measurements were carried out at a distance of $4 \mathrm{~cm}$ between the camera and the slab's surface, corresponding to a $34 \times$ $25 \mathrm{~mm}$ area. The image captured by the CCD camera was composed of $640 \times 480$ pixels.

During the experiment, the measurements were performed on the central part of the slabs, which were pre-conditioned in the dark. The initial fluorescence $\left(\mathrm{F}_{0}\right)$ was obtained after 30 minutes of dark adaptation. Maximal fluorescence $\left(\mathrm{F}_{\mathrm{m}}\right)$ was obtained with a saturating flash $\left(1 \mathrm{~s}, 1000 \mu \mathrm{mol} \cdot \mathrm{m}^{-2} \cdot \mathrm{s}^{-1}\right)$. The ratio of variable to maximal fluorescence $\left(\mathrm{F}_{\mathrm{v}} / \mathrm{F}_{\mathrm{m}}=\left(\mathrm{F}_{\mathrm{m}}-\mathrm{F}_{0}\right) / \mathrm{F}_{\mathrm{m}}\right)$ was calculated. The protocol for fluorescence measurement was similar to the one described by [49]. The relative quantum yield of PSII $\left(\Phi_{\text {PSII }}\right)$ at steady state is defined as $\left(\mathrm{F}_{\mathrm{m}^{\prime}}-\mathrm{F}_{\mathrm{s}}\right) / \mathrm{F}_{\mathrm{m}^{\prime}}$, where $\mathrm{F}_{\mathrm{s}}$ and $\mathrm{F}_{\mathrm{m}^{\prime}}$ are, respectively, steady-state fluorescence and maximum fluorescence in the light $\left(\mathrm{PAR}=120 \mu \mathrm{mol}\right.$ photon. $\left.\mathrm{m}^{-2} \cdot \mathrm{s}^{-1}\right)$. $\Phi_{\mathrm{PSII}}$ represented the number of electrons transported by a PSII reaction centre per mole of quanta absorbed by PSII. Both photochemical $\left(\mathrm{q}_{\mathrm{P}}\right)$ and non-photochemical quenching $\left(\mathrm{q}_{\mathrm{N}}\right)$ were calculated according to [50].

\subsubsection{Water vapour permeability}

The diffusion of water vapour through stone is one of the properties of hydrophobic coatings. The Standard NF EN 15803 [51] details its measurement on coated stone discs $50 \mathrm{~mm}$ in diameter and 1.6 mm thick. Discs were sealed in a glass cup containing water and placed in a dry keeper with a relative humidity around $53 \%$ with a saturated solution of magnesium nitrate at $20 \pm 2^{\circ} \mathrm{C}$. Triplicates for natural stones (control) and coated stones are used and the apparatus of disc in glass cup are weighted before and every $24 \mathrm{~h}$ until stabilisation of the weight. The water vapour permeability $\left(\delta_{\mathrm{p}}\right)$ was calculated with the following formula and the mean was computed from the three measurements of control and coated stones: 
$\delta_{\mathrm{p}}=\frac{\mathrm{G}}{\mathrm{A} \cdot \Delta \mathrm{p}_{\mathrm{v}}} \cdot \mathrm{D}\left(\mathrm{kg} \cdot \mathrm{m}^{-1} \cdot \mathrm{s}^{-1} \cdot \mathrm{Pa}^{-1}\right)$

with $\quad \mathrm{G}=\Delta \mathrm{m} / \Delta \mathrm{t}\left(\mathrm{kg} \cdot \mathrm{s}^{-1}\right)$ : the slope of the linear part of the curve corresponding to the mass variation in function of the time

A: surface of the disc $\left(\mathrm{m}^{2}\right)$

$\Delta \mathrm{p}_{\mathrm{v}}$ : variation of water vapour pressure on both sides of the cup (Pa)

D: thickness of the disc (m)

Then the reduction of the water vapour permeability $\left(\delta_{\mathrm{p} \mathrm{red}}\right)$ was calculated from the Standard NF EN 16581 [52], according to the formula:

$\delta_{\text {p red }}(\%)=\frac{\delta \mathrm{p} \mathrm{n}-\delta p c}{\delta p c} .100$

with : $\delta_{\mathrm{p} n}$ water vapour permeability of natural stone $\left(\mathrm{kg} \cdot \mathrm{m}^{-1} \cdot \mathrm{s}^{-1} \cdot \mathrm{Pa}^{-1}\right)$

$\delta_{\mathrm{pc}}$ water vapour permeability of coated stone $\left(\mathrm{kg} \cdot \mathrm{m}^{-1} \cdot \mathrm{s}^{-1} \cdot \mathrm{Pa}^{-1}\right)$

\subsubsection{Static contact angles}

The wettability of the stone surface was monitored by the measurements of static contact angles $(\theta)$, often used to assess the hydrophobic effect of coatings. They were performed on the coated surfaces before and after each step of ageing test $(42,84,126$ and 168 cycles).

For each measurement, a water droplet $(5 \mu \mathrm{l})$ was deposited on the surface of the stone at room temperature [53]. The angle made by the water droplet on the stone surface was defined geometrically as the angle formed by the liquid at the three-phase boundary where liquid, gas and solid intersect. It was calculated by computer analysis with the software See System (Advex Instruments) of digital images from the picture of the droplet on the surface after 10 min. Sixteen measurements were performed on each sample, averaging the results. We underline that Dom stone has a high surface roughness that could induce a non-ideal flat basis for the calculation of the angles, which could result in high standard deviations (Supplementary Table S11).

\subsubsection{Scanning Electron Microscopy (SEM) combined to energy dispersive spectroscopy $(E D S)$}

Environmental SEM-EDS was used in order to observe the coating on the surface stone and to evaluate the effect of the aging on the morphology of coated stones and control. The apparatus was a SEM Hitachi TM-3030 plus Tabletop Microscope with an energy-dispersive X-ray spectrometer (Swifted-TM Energy Dispersive XRay). Samples introduced in the microscope had a dimension of $2 \mathrm{~cm}$ $\mathrm{x} 1 \mathrm{~cm} \times 0.5 \mathrm{~cm}$ and were placed on a double-sided adhesive carbon tape. The accelerating voltage was $15 \mathrm{kV}$ for imaging. The working distance was $6 \mathrm{~mm}$. All images were acquired in the back-scattered electron mode.

\subsubsection{Porosity and pore access radii}

The microstructural characteristics of uncoated and coated stones were assessed through the mercury $(\mathrm{Hg})$ intrusion measurements to evaluate the modification of the porous network involved by the application of coatings on the stone surface.

Data were obtained with a mercury intrusion porosimeter (Micromeritics Autopore IV 9500), reaching a pressure of $247 \mathrm{MPa}$ and measuring pore radii sizes from 0.003 to $178 \mu \mathrm{m}$. One sample $(1 \mathrm{x} 1 \mathrm{~cm})$ of control (uncoated stone), TCAg-7 and TCAg-14 coated stone was analysed before and at the end of the artificial ageing.

\subsection{Statistics}

299 
The open-source software R [54] has been used to compute statistics and to produce all graphics, with the following packages: ggplot2 [55], R. utils [56], doBy [57], readxl [58] and devEMF [59].

\section{Results and discussion}

\subsection{Colour change after coating}

The colour change of stone involved after the application of coatings is as important as the performance of the coating itself. The generally accepted requirement is that no colour change can be visually noticed [60]. This depends on the stone; it ranges from $\Delta \mathrm{E}_{\mathrm{ab}}^{*} \leq 3[6,61]$ to $\Delta \mathrm{E}^{*}{ }_{\mathrm{ab}}<6$ [62]. For the Dom stone, the threshold for no visual colour change was set to $\Delta \mathrm{E}_{\mathrm{ab}}^{*} \leq 4$ (Fig. 1a). A global trend of increasing $\Delta \mathrm{L}^{*}$ with $\Delta \mathrm{h}^{*}$ ab could be observed $\left(\mathrm{R}^{2}=0.7, \mathrm{p}<0.001\right.$; Fig. $\left.1 \mathrm{~b}\right)$. Therefore, the global colour change resulted from the darkening and reddening of stones.

The colour change was most significant with the highest quantity of water repellent (T-14 and TCAg14). Chitosan mixed with the water repellent (TC-7, $\mathrm{TC}^{+}-7$ and $\mathrm{TC}^{++}-7$ ) changed colour below the required threshold $\left(\Delta \mathrm{E}_{\mathrm{ab}}^{*} \leq 4\right)$, as did the low dose of water repellent (T-7 and TCAg-7).

When $\mathrm{AgNO}_{3}$ was added (TCAg-7), $\Delta \mathrm{E}_{\text {ab }}^{*}$ was most similar to that of $\mathrm{T}-7$ (no biocide). However, $\Delta \mathrm{L}^{*}$ and $\Delta \mathrm{h}^{*}$ ab were lower, suggesting that the addition of $\mathrm{AgNO}_{3}$ to the water repellent (with or without chitosan) does darken and redden the stone. Furthermore, an increase in the dose of water repellent in $\mathrm{T}-14$, as compared to $\mathrm{T}-7$, increased dramatically the global stone colour to 6.4 due to an important darkening $\left(\Delta \mathrm{L}^{*}=-4.5\right)$. The addition of biocides to T-14 (i.e. TCAg-14) amplified the darkening and shifted the hue to even redder colours. Accordingly, the least amount of colour change was observed for the coating with the lowest dose of chitosan and water repellent (TC-7).
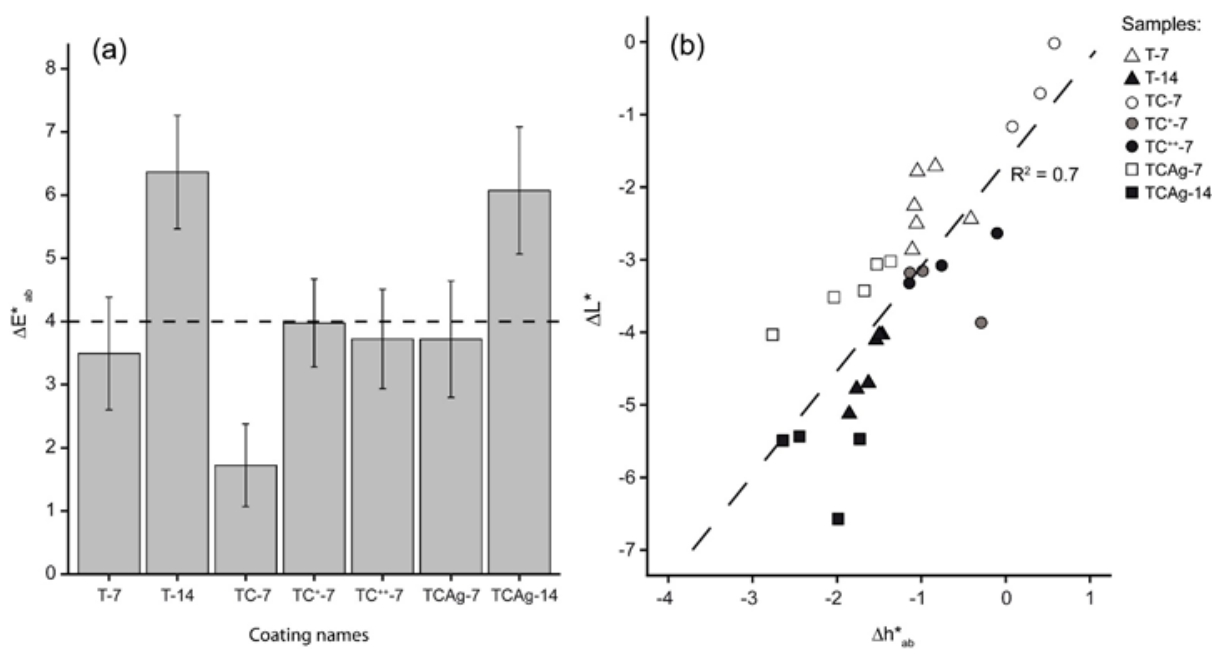

\subsection{Biocide effect}

The accelerated biofouling allowed the testing of the biocide effect of coatings containing different concentrations of chitosan, combined or not with silver nitrate. The colour parameter $\Delta \mathrm{a}^{*}$ was used to follow the development of Chlorella vulgaris over time [63,64]. The other calculated colour parameters were also analysed but their results (not shown) were similar to $\Delta \mathrm{a}^{*}$, except for $\Delta \mathrm{b}^{*}$, which mirrored far less the algae development.

Control samples displayed negative $\Delta \mathrm{a}^{*}$ which decreased progressively over time, although they increased slightly in the last week (Fig. 2a). This is mirrored by an algal development on stone surfaces. $\mathrm{F}_{\mathrm{v}} / \mathrm{F}_{\mathrm{m}}, \phi_{\text {PSII }}, \mathrm{q}_{\mathrm{N}}$ and $\mathrm{q}_{\mathrm{p}}$ data of control indicated that the highest photosynthetic activity occurred during the first test week, implying an early algae settlement on stone. The fast decrease of $\phi_{\text {PSII }}$ during the second week represented a lower effective photosynthetic activity of PSII (Fig.2b). This can be explained by the decrease of $\mathrm{q}_{\mathrm{P}}$ (Fig. 2c) and thus by a decrease in the electron transfer from the PSII to the PSI. Nevertheless, $\mathrm{q}_{\mathrm{N}}$ continued to increase during the second week and then became stagnant during 
the last two weeks (Fig.2d). These results represented heat dissipation and corresponded to a regulation of an excess of electrons and to an adaptation of the algal population. The progressive decrease of the photosynthetic activity was therefore due to the senescence of the first algae and to the adaptation to the substrate, which took eight test weeks in a previous study [31].
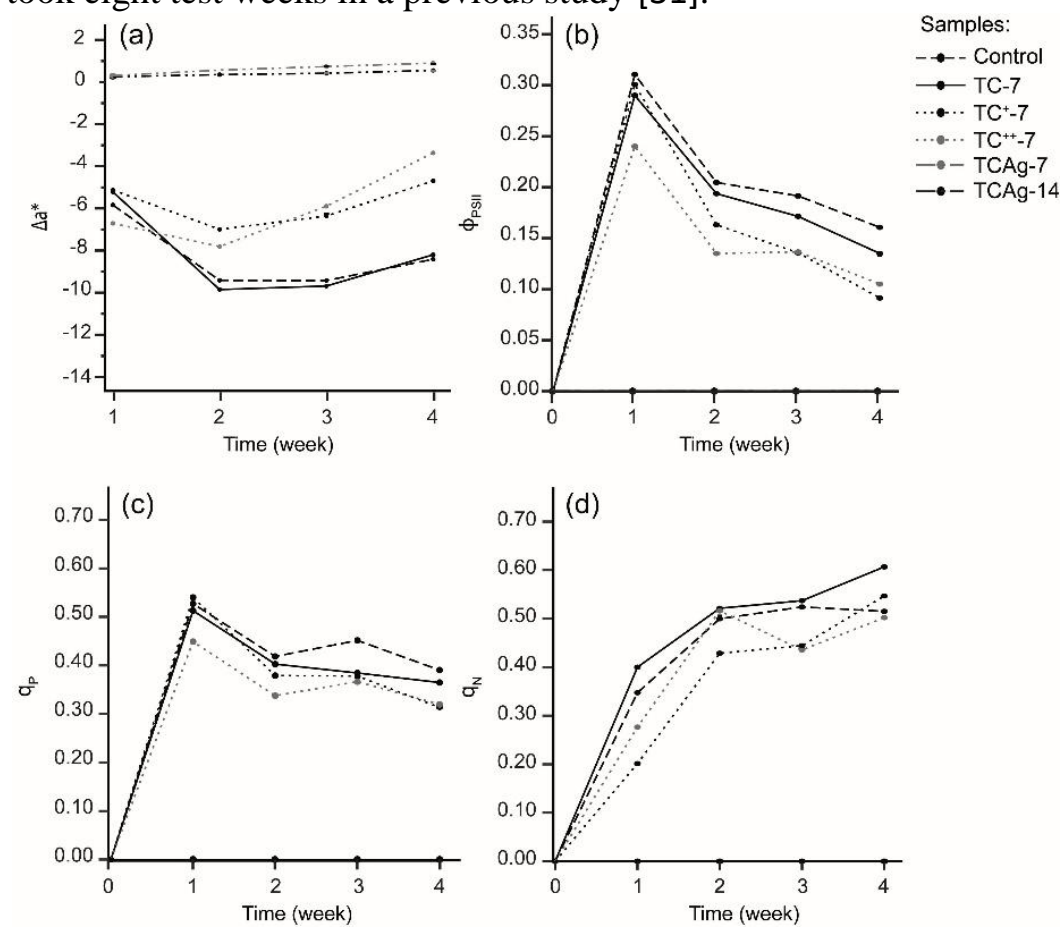

Fig. 2. Mean of $\Delta \mathrm{a}^{*}$ of triplicates calculated from measurements before incubation and after 1,2,3 and 4 weeks of incubation (a). Evolution of $\mathrm{Chl}$ a fluorescence parameters of PSII ( $\phi$ PSII, the effective quantum yield) in Chlorella vulgaris in triplicates of control and coated stones after 1, 2, 3 and 4 weeks of incubation (b), qP (the photo-chemical quenching) (c), qN (the non photo-chemical quenching that is the heat dissipation) (d). See Supplementary Tables S3-S6 for means and standard deviations.

Three response patterns could be observed from the biofouling analysis of the coated stones. The first one, displayed by TC-7, was very similar to that of the control (Figs. 2-3), proving the same algae development and the lack of biocide efficacy. The concentration of chitosan was apparently not sufficient to avoid the algal development. The second pattern grouped $\mathrm{TC}^{+}-7$ and $\mathrm{TC}^{++}-7$ coatings. $\Delta \mathrm{a}^{*}$ was negative throughout the test, corresponding to a greening on stones. Nonetheless $\Delta \mathrm{a}^{*}$ was less negative than control and increased after the second week, suggesting a decrease in the greening. $F_{v} / F_{m}$ showed a decline of the maximal PSII quantum yield by a shift from a blue colour in the first week to a green one the next weeks (Fig.3). Moreover, $\phi_{\mathrm{PSII}}$ and $\mathrm{q}_{\mathrm{P}}$ values were lower than control and more so for $\mathrm{TC}^{++}-7$. Thus, the effective activity of the PSII decreased and both coatings acted on the algal development by limiting the electron transfer in the photosynthetic chain. $\mathrm{q}_{\mathrm{N}}$ highlighted a heat dissipation lower than in the control slabs, pointing out that the algae did not manage to regulate as well the excess of electrons by heat dissipation. Accordingly, $\mathrm{TC}^{+}-7$ and $\mathrm{TC}^{++}-7$ had a biocide effect and acted on the vital functions of algae but they could not fully avoid their development. An increase of chitosan doses should improve even further its efficacy but that would likely induce a colour change of stone too strong to be acceptable.

The third response pattern was displayed by TCAg-7 and TCAg-14, which showed a weak positive $\Delta \mathrm{a}^{*}$, meaning a lack of greening on stones. Chl. $a$ fluorescence measurements stayed nil throughout the test, which proved that no photosynthetic activity took place. Therefore, the addition of a weak concentration of silver nitrate to chitosan and a silane/siloxane emulsion had a significant biocide impact. Even though chitosan did not reach an optimal effect alone, a previous study [31] clearly displayed that the combination of chitosan with low doses of $\mathrm{AgNO}_{3}$ and hydrophobic silica can have the same effect as higher doses of $\mathrm{AgNO}_{3}$ alone or with hydrophobic silica. Achieving the same biocide effect with lower doses of $\mathrm{AgNO}_{3}$ is a great improvement for the environmental implications. 


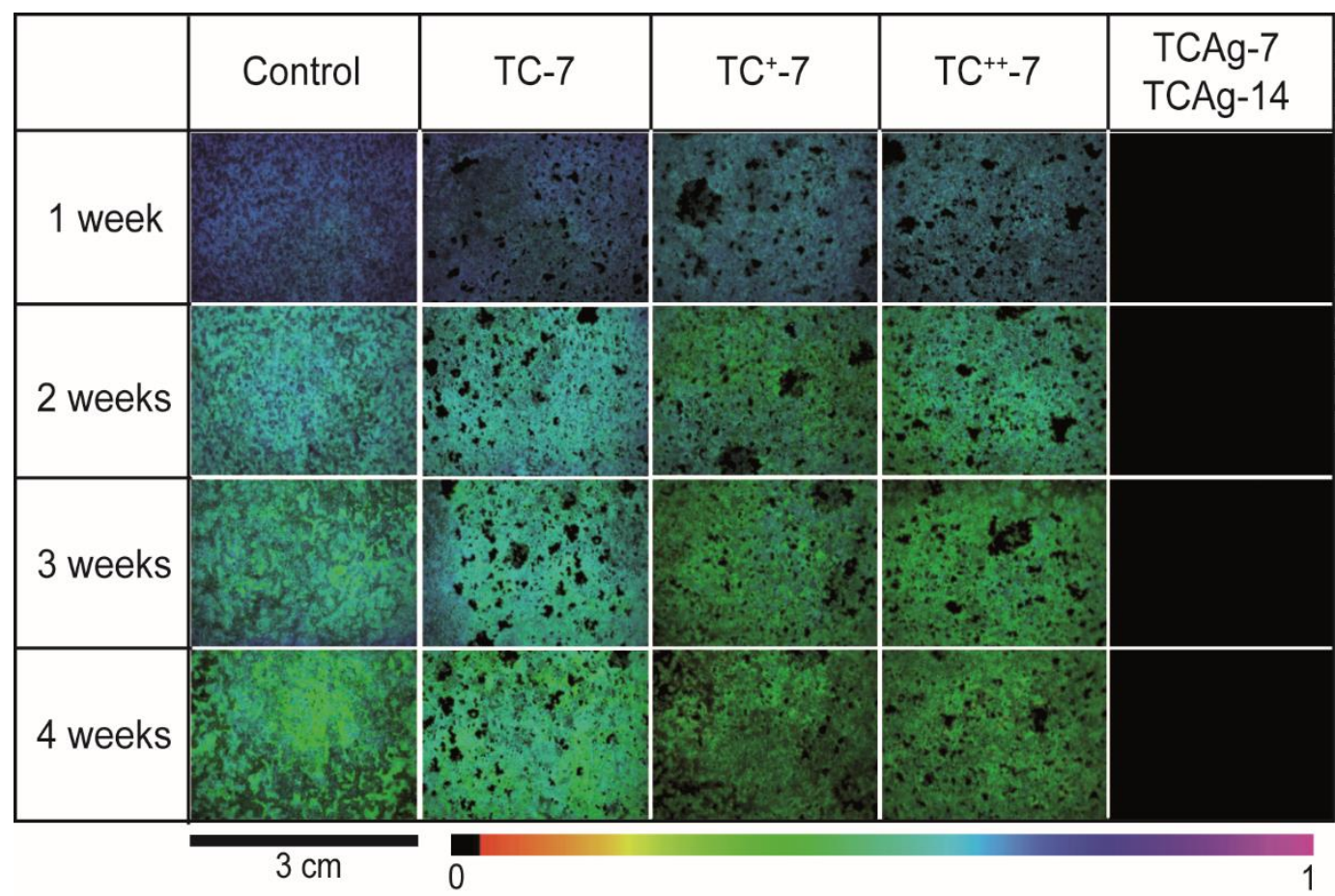

Fig. 3. Fluorescence imaging of the dynamic evolution of chlorella vulgaris inoculated in control and coated stones. Samples were dark-adapted for $30 \mathrm{~min}$ and submitted to saturation pulse. A photo of photosynthetic efficiency (Fv/Fm) was captured every test week. The false colour code ranges from black (0.000) to pink (1.000). See Supplementary Table S7 for means and standard deviations. (For interpretation of the references to colour in this figure legend, the reader is referred to the web version of this article.)

\subsection{Properties of coated stones in artificial ageing test}

TCAg-7 and TCAg-14 coatings were selected for the ageing test because of their optimal biocide effect during the accelerated biofouling test (see section 3.2). They were then tested for their durability, hydrophobicity and changes in stone properties throughout an artificial ageing test.

\subsubsection{Coatings integrity}

The distribution of the coatings on the surface of the stone was observed by SEM and analysed by EDS. Before the ageing test, the EDS analysis measured high peaks of calcium in uncoated stones, as expected for a limestone (Fig 5a). On coated stones, the coating was not observed on the major stone surface at this scale of observation. A small peak of Silicon $(\mathrm{Si})$ allowed its detection on calcite grains that attested the presence of the Si-O network in the whole stone surface (Fig 5b). The concentrations of Si on calcitic grains were very variable as displayed by the means from six measured spots (Table 3 ) and depended probably on the thickness of coatings. Nevertheless, the coating could be clearly observed as a coating flooding grains and partially filling the porosity (Fig 5c). It was characterised by a higher proportion of Si than on calcitic grains and a higher variability that depended on the thickness too.

The viscosity of $\mathrm{HY}$ is $3.20 \mathrm{mPa}$.s, which is common for other hybrid polymers with values around 2$3.3 \mathrm{mPa}$.s [65]. The evaporation of the solvent probably happened too fast and limited the entire penetration into the stone or there was a competition between the dissolution of stone (as showed $\mathrm{Hg}$ measurements) and the polymerisation.

Partial glazing has already been observed with a nano-composite $\mathrm{SiO}_{2} / \mathrm{CuONPs}$, which modified the topography locally [24]. On stones coated with TCAg-14 (higher dose than TCAg-7), the glazing could be observed in the roughest areas. TG-coatings, corresponding to the application of only the water repellent, were observed for comparison (Fig. 5d). They showed the same result, suggesting that they are related to the water repellent itself and not to the polysaccharide network of chitosan in HY. After the ageing, SEM observations on coated stones showed local compact films were disrupted as patches 
on the surface (Fig 6a) and cracks were locally observed in coatings (Fig 6b). They revealed the erosion of the film in the face of the weathering simulation.
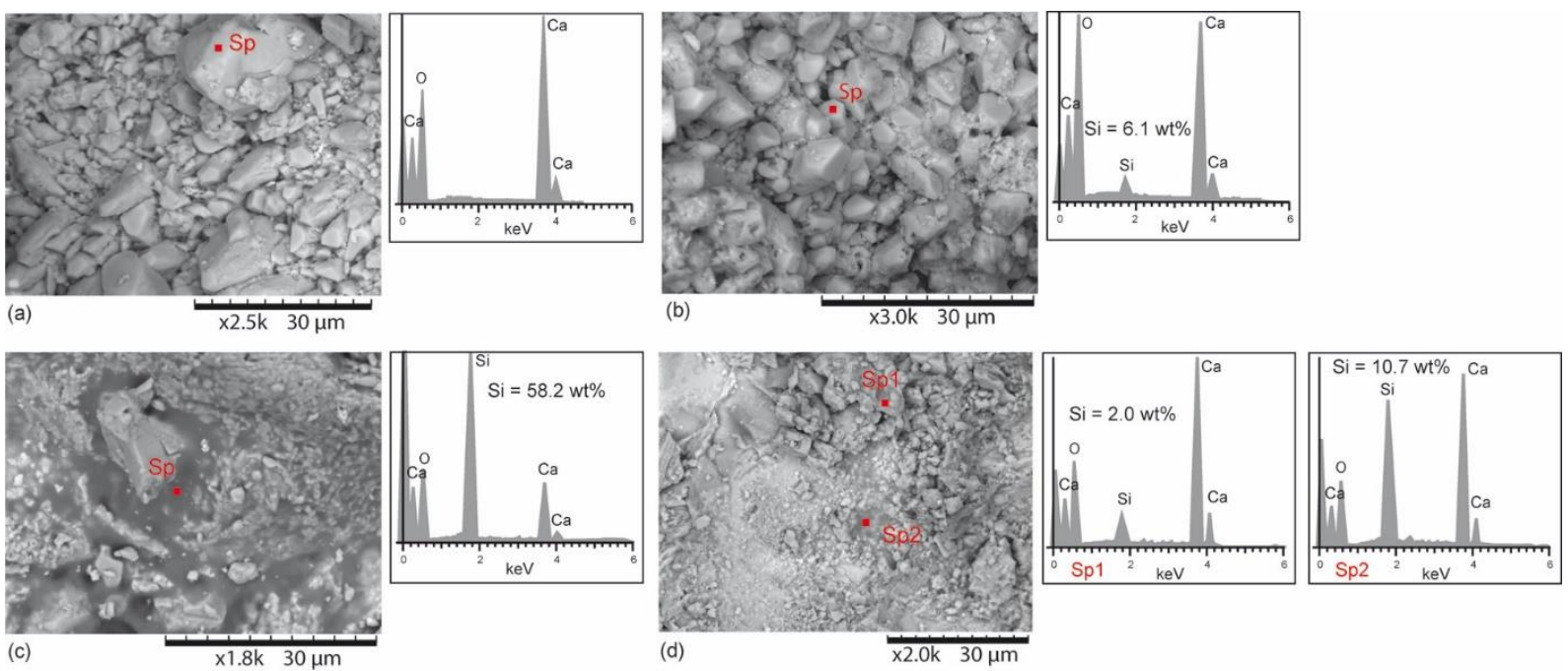

\subsubsection{Colour change}

The artificial ageing test was carried out on coatings TCAg-7 and TCAg-14 with both biocides and water repellent, and compared to T-7 and T-14 coatings (water repellent only with different applied quantities) (Table 1). The colour changes of stones induced by those coatings have been discussed in section 3.1. The evolution of the stone colour along the ageing test was measured after 42, 84, 126 and 168 cycles.

Control slabs showed the highest global variations of colour (Fig. 7a). These variations corresponded to a darkening of the stone throughout the ageing process, as reflected by the decrease of $\Delta \mathrm{L}^{*}$ while the hue $\left(\Delta \mathrm{h}_{\mathrm{ab}}^{*}\right)$ stayed stable (Fig. $\left.7 \mathrm{~b}\right)$. The uncoated Dom stone is therefore influenced by the sunlight and rain simulated in a climatic chamber. The colour variation over time depends on the type of stone: Luvidi et al. [25] showed that the uncoated Lecce stone had $\Delta \mathrm{E}_{\mathrm{ab}}^{*}>15$, whereas $\Delta \mathrm{E}_{\mathrm{ab}}^{*}<2$ for the uncoated marble after an outdoor exposure.

In our study, all coated stones had lower colour changes than control ones and never exceeded 4 except for TCAg-14 (highest value $=4.26$ ). The lowest $\Delta \mathrm{E}_{\text {ab }}^{*}$ were measured for T-7 and for TCAg-7. Those coatings had a stable colour over time. In details, the lightness of T-7 and TCAg-7 was stable over time as well ( $\Delta \mathrm{L}^{*}$ was around 1 for T-7 and close to 0 for TCAg-7). Nevertheless, the addition of chitosan and silver nitrate to Tegosivin ${ }^{\circledR}$ (TCAg-7) increased the variation of the hue (3.4 instead of 0.9 for T-7) which corresponded to a more yellowish stone. This trend increased throughout the ageing.

$\Delta \mathrm{E}_{\mathrm{ab}}^{*}$ increased with higher quantities of Tegosivin ${ }^{\circledR}$ (T-14), especially from 84 cycles onwards, which can be explained by a net lightening (Fig. 7b). Therefore, the colour of the water repellent changed with the accelerated ageing and with increasing dose.

When both chitosan and silver nitrate were added to T-14 formulation (i.e. TCAg-14), the global colour change was generally higher than TCAg-7. In details, the coating did not influence the lightness over cycles and the colour shifted to yellow tones as for TCAg-7 but standard deviations of $\Delta \mathrm{L}^{*}$ and $\Delta \mathrm{h}^{*}$ ab (Supplementary Tables S9-S10) are much higher than for TCAg-7 and displayed an heterogeneity of TCAg-14 through time.

Accordingly, all coatings stabilised the stone colour despite the exposure to sunlight and rain in chamber, as compared to the uncoated stone. Higher dose of water repellent changed the colour by fading. The addition of biocides did not induce great global change $(\Delta \mathrm{E}<5)$. They stabilised the lightness but the hue did increase, meaning that the stone colour evolved toward yellow tones for both HY coated stones. 
Nonetheless, the best coating gathering hydrophobic and biocide effects seems to be TCAg-7 because it does not induce important colour changes over time either.

\subsubsection{Porous network}

The application of coatings, without artificial ageing, led to an increase in the $\mathrm{Hg}$ porosity of the stone (Table 2). It was reflected by a shift of the peak for the major pore access radius from $1.8 \mu \mathrm{m}$ in the control samples to $3.5 \mu \mathrm{m}$ for both TCAg-7 and TCAg-14 coated stones, while the pore size distribution stayed bimodal (Fig.4a). Moreover, the increase of the $\mathrm{Hg}$ intrusion for every class of the pore access radii for both coated stones (except for TCAg- 7 in the 10-1 $\mu$ m class) evidenced the enlargement of pore size (Table 2). These results revealed a dissolution of pores probably induced by the slight acidity of Tegosivin ${ }^{\circledR} \mathrm{HE} 328$ which has $\mathrm{pH}=6$, but $\mathrm{HY}$ has $\mathrm{pH}=4$ due to the use of lactic acid to solubilize the chitosan powder which had not fully reacted. This could explain the dissolution of the stone that occurred during the application of the coating.

The porosity of the control was higher after the ageing test ( $28.6 \%$ instead of $21.4 \%$ before the ageing). The $\mathrm{Hg}$ intrusion increased for every class of pore access (Table 2), pointing to a development of the porous network. In details, there was a widening of the largest pore access radii from 1.8 $\mu \mathrm{m}$ to $4-7 \mu \mathrm{m}$ (Fig.4b) and an increase of the pore access radii between 1-0.1 $\mu \mathrm{m}$ and 10-1 $\mu \mathrm{m}$. Therefore, artificial weathering dissolved the fresh uncoated stone.

The ageing on the coated stones also increased their porosity but the difference before and after ageing was weaker than for the non-coated stone. That was displayed by a significant development of the pore radii bigger than $10 \mu \mathrm{m}$ for TCAg-14 where the peak of the biggest pore radius shifted to $14 \mu \mathrm{m}$ (Fig.4c) and the $\mathrm{Hg}$ intrusion for this pore class increased from 0.011 to $0.038 \mathrm{~mL} \cdot \mathrm{g}^{-1}$ (Table 2). For TCAg-7, the bigger pore radius reached $5 \mu \mathrm{m}$ and a second one $1 \mu \mathrm{m}$ (Fig.4c); there was an increase in $\mathrm{Hg}$ intrusion, and thus an increase of pores bigger than $10 \mu \mathrm{m}$ and between 10 and $1 \mu \mathrm{m}$ (Table 2). Consequently, the weathering enlarged all pore radius classes in the natural stone, whereas in the stone coated with TCAg-7, the enlargement was noticed in both bigger and medium classes and in the stone coated with TCAg-14 mainly in the bigger class. The coatings limited the enlargement of medium and smaller pores but the most significant impact occurred in the class of pores bigger than $10 \mu \mathrm{m}$ on stones with the highest dose of coating.

\subsubsection{Performance of the hydrophobic effect}

The two next tests are part of the NF EN 16581 Standard for the evaluation of the water repellency of coatings.

\subsubsection{Water vapour permeability}

The water vapour transfer was measured only before the ageing test because the thin stone discs required could not be used in the climatic chamber where the water spray would blow and move them. It was measured from the inside of the coated stones toward the external surface.

The reduction of water vapour permeability $\left(\delta_{\mathrm{p} \text { red }}\right)$ of the coated stones could be explained by the widening of the porous network due to dissolution during the application of the coating combined with the hydrophobicity of the coating. Diffusion depends on tortuosity of the porous network, adsorption films and capillary condensation meniscus [66-69]. The widening of pore access radii in the coated stones limited the capillary condensation in the porous network as well the hydrophobicity of the grains and thus limited diffusion. $\delta_{\text {p red }}$ was below or close to the $20 \%$ threshold (Table 4 ). This suggests that all coatings fit the requirement for hydrophobic coatings [60]. Moreover, all $\delta_{\text {p red }}$ were similar, implying that the adjunction of biocides or increasing the dose of water repellent did not greatly modify the properties of the water repellent.

Pia et al. [12] noted the low permeability of experimental nano-structured organic and inorganic coatings and used the transmission degree of water vapour (V) to test vapour permeability on hybrid coatings. 
Three classes were used, class I with $\mathrm{V}>150 \mathrm{~g} \mathrm{~m}^{-2} \cdot \mathrm{d}^{-1}$, class II with $15<\mathrm{V}<150 \mathrm{~g} \cdot \mathrm{m}^{-2} \cdot \mathrm{d}^{-1}$ and class III with $\mathrm{V}<15 \mathrm{~g} \cdot \mathrm{m}^{-2} \cdot \mathrm{d}^{-1}$. Our four coatings had values ranging between 163 and $177 \mathrm{~g} \cdot \mathrm{m}^{-2} \cdot \mathrm{d}^{-1}$ and thus all belong to class I, corresponding to a high transmission degree of water vapour. In comparison, the boehmite/siloxane-modified metacrylic coatings of Esposito et al. [70] achieved a transmission degree of water vapour on two carbonate stones of 17.3 and $7.0 \mathrm{~g} \cdot \mathrm{m}^{-2} \cdot \mathrm{d}^{-1}$. Accordingly, the coatings in the present study have a good performance in the transmission of water vapour through the stone.

\subsubsection{Static contact angle}

The static contact angle was measured before and at every stage of the artificial ageing in order to confirm the efficacy of the water repellent and to define the possible interaction between the water repellent and the biocide components.

Directly after application, contact angles ranged between $122.8^{\circ}$ and $129.4^{\circ}$ (Fig.8), higher than the minimum requirement of $90^{\circ}$ [60]. Thus, all coatings had a good hydrophobicity.T-14 coating had the highest value whereas TCAg-14 had the lowest one. The addition of biocides seemed to interfere with the performance of the water repellent; nonetheless, T-7 and TCAg-7 had the same contact angles. Hence, the interference appeared to occur only at higher concentrations of the water repellent. This warrants further investigation.

Throughout the ageing, T-14 had the highest contact angles compared to the other coatings (Fig.8). Moreover, values were even higher at the end of the experiment. The enhancement of performance after an artificial ageing test was already noted with a coating based on silsesquioxane and aged in climatic chamber at $40^{\circ} \mathrm{C}[71]$. The authors explained this result by the enhancement in the networking of the polymeric structure thanks to temperature during the ageing test.

T-7 and TCAg-14 showed a net decline of the contact angles after 42 cycles and until 126 cycles; the hydrophobicity then increased to reach $117.2^{\circ}$ and $119^{\circ}$, respectively at the end of the ageing. Contact angles of TCAg-7 were stable until 84 cycles and decreased as the other coatings at 126 cycles but less drastically. At the end of the test, TCAg-7 had a hydrophobicity close to T- 7 and TCAg-14.

This downward and then upward trend of the static contact angle has also been described with another organic-inorganic hybrid coating subjected to a UV and water-condensation weathering in climatic chamber. The contact angle decreased progressively from $140^{\circ}$ to $110^{\circ}$ during 120 days with a minimum of $105^{\circ}$ [20]. Nonetheless, variability of our data increased at 126 and 168 cycles and reflected an increase in the heterogeneity of the hydrophobicity at the stone surface despite the contact angle staying close to $90^{\circ}$.

Comparison of both coatings with hydrophobic and biocide effects revealed that the best hydrophobicity was not achieved with the highest dose of water repellent when associated to biocides. TCAg-7, with its lower quantity of Tegosivin ${ }^{\circledR} \mathrm{HE} 328$, had an intermediate but stable efficacy over time.

\section{Conclusions}

Different coatings were prepared in the goal of achieving a biocide and hydrophobic efficacy by means of sol-gel process and the combination of a hybrid polymer with a natural biocide as chitosan. This last component did not change the stone colour and a coating with $13.6 \mathrm{~g} / \mathrm{L}$ of chitosan is enough to disturb the photosystem of algae. However, it could not fully stop their development and a higher concentration could probably reach an optimal impact but at the expense of a higher colour change. Nonetheless, this shortcoming was compensated by supplementing a weak dose of silver nitrate. This low concentration of silver nitrate was efficient only when associated to the chitosan and the water repellent. Two doses of this formulation were investigated. Their application on stone induced a low change of colour and a good hydrophobicity. The analyses showed that the coatings spread over the whole stone surface as a thin film and flooded grains in local zones as well. They invaded the open porosity but they increased the latter by enlarging the pores during their application due to the low $\mathrm{pH}$ of solution. In further work, the formulations should be improved by limiting the colour change and increasing the $\mathrm{pH}$ induced by the solubilisation of the chitosan. This would ultimately allow the use of chitosan only, at higher concentrations than tested in the present study. 
The artificial ageing test revealed a moderate colour variation on coated stones, whereas the natural stone reached the highest colour change over time. The simulation of rainfall caused the enlargement of pores and eroded the films in patches but the hydrophobic effect was not inhibited.

The best coating combining a weak dose of water repellent with chitosan and silver nitrate (TCAg- 7) had a good biocide and hydrophobic efficacy while preserving the natural aspect of the stone. Furthermore, using low doses of silver nitrate also limits the negative impacts of this compound on the environment and health. These results obtained in laboratory conditions must be confirmed in a longterm outdoor test to evaluate the durability of coatings in a real exposure to the environment with all existing variables.

\section{Acknowledgments}

This work is funded by Interreg IV European grant (Hybriprotech project), co-financed by FEDER, Région Champagne-Ardenne, Conseil général des Ardennes, Conseil général de la Marne and la Wallonie. The authors are grateful to Michaël Molinari and Nicolae Bogdan-Bercu from the Laboratoire de Recherche en Nanosciences of University of Reims Champagne-Ardenne and Nathalie Choiselle from ESI REIMS.

\section{References}

[1] R. Prikryl, H.A. Viles, Understanding and managing of Stone decay (SWAPNET 2001), Charles University: The Karolinum Press, Prague, Czech Republic, 2002. http://www.bcin.ca/Interface/openbcin.cgi?submit=submit\&Chinkey=403357 (accessed June 30, 2017).

[2] M. Steiger, A.E. Charola, Weathering and Deterioration, in: Stone Archit. 4th Ed, Springer-Verlag Berlin Heidelberg, Siegesmund S, Snethlage R, Berlin, 2001: pp. 227-316.

[3] D. Camuffo, Physical weathering of stones, Sci. Total Environ. 167 (1995) 1-14. doi:10.1016/0048-9697(95)04565-I.

[4] C. Cardell-Fernández, G. Vleugels, K. Torfs, R.V. Grieken, The processes dominating Ca dissolution of limestone when exposed to ambient atmospheric conditions as determined by comparing dissolution models, Environ. Geol. 43 (2002) 160-171. doi:10.1007/s00254-002-0640$\mathrm{x}$.

[5] A. Saad, S. Guédon, F. Martineau, Microstructural weathering of sedimentary rocks by freezethaw cycles: Experimental study of state and transfer parameters, Comptes Rendus Geosci. 342 (2010) 197-203. doi:10.1016/j.crte.2009.12.009.

[6] A. Burgos-Cara, E. Ruiz-Agudo, C. Rodriguez-Navarro, Effectiveness of oxalic acid treatments for the protection of marble surfaces, Mater. Des. 115 (2017) 82-92. doi:10.1016/j.matdes.2016.11.037.

[7] A.E. Charola, Water Repellents and Other "Protective" Treatments: A Critical Review, Restor. Build. Monum. 9 (2003) 3-22. doi:10.1515/rbm-2003-5727.

[8] D. Yang, J. Li, Y. Xu, D. Wu, Y. Sun, H. Zhu, F. Deng, Direct formation of hydrophobic silicabased micro/mesoporous hybrids from polymethylhydrosiloxane and tetraethoxysilane, Microporous Mesoporous Mater. 95 (2006) 180-186. doi:10.1016/j.micromeso.2006.05.022.

[9] B. Simionescu, M. Olaru, Assessment of siloxane-based polymeric matrices as water repellent coatings for stone monuments, Eur. J. Sci. Theol. 5 (2009) 59-67.

[10] P. Fermo, G. Cappelletti, N. Cozzi, G. Padeletti, S. Kaciulis, M. Brucale, M. Merlini, Hydrophobizing coatings for cultural heritage. A detailed study of resin/stone surface interaction, Appl. Phys. Mater. Sci. Process. 116 (2014) 341-348. doi:10.1007/s00339-013-8127-z.

[11] I. Karapanagiotis, A. Pavlou, P.N. Manoudis, K.E. Aifantis, Water repellent ORMOSIL films for the protection of stone and other materials, Mater. Lett. 131 (2014) 276-279. doi:10.1016/j.matlet.2014.05.163.

[12] D. Aslanidou, I. Karapanagiotis, C. Panayiotou, Tuning the wetting properties of siloxanenanoparticle coatings to induce superhydrophobicity and superoleophobicity for stone protection, Mater. Des. 108 (2016) 736-744. doi:10.1016/j.matdes.2016.07.014. 
[13] I. Alfieri, A. Lorenzi, L. Ranzenigo, L. Lazzarini, G. Predieri, P.P. Lottici, Synthesis and characterization of photocatalytic hydrophobic hybrid $\mathrm{TiO} 2-\mathrm{SiO} 2$ coatings for building applications, Build. Environ. 111 (2017) 72-79. doi:10.1016/j.buildenv.2016.10.019.

[14] A.E. Charola, C. McNamara, R.J. Koestler, Biocolonization of Stone: Control and Preventive Methods: Proceeedings from the MCI Workshop Series, Smithson. Contrib. Mus. Conserv. (2011) 1-115. doi:10.5479/si.19492359.2.1.

[15] O. Guillitte, R. Dreesen, Laboratory chamber studies and petrographical analysis as bioreceptivity assessment tools of building materials, Sci. Total Environ. 167 (1995) 365-374. doi:10.1016/0048-9697(95)04596-S.

[16] M.E. Young, H.-L. Alakomi, I. Fortune, A.A. Gorbushina, W.E. Krumbein, I. Maxwell, C. McCullagh, P. Robertson, M. Saarela, J. Valero, M. Vendrell, Development of a biocidal treatment regime to inhibit biological growths on cultural heritage: BIODAM, Environ. Geol. 56 (2008) 631-641. doi:10.1007/s00254-008-1455-1.

[17] S. Manso, M. De, I. Segura, A. Aguado, K. Steppe, N. Boon, B. De, Bioreceptivity evaluation of cementitious materials designed to stimulate biological growth, Sci. Total Environ. 481 (2014) 232-241. doi:10.1016/j.scitotenv.2014.02.059.

[18] W. De Muynck, N. De Belie, W. Verstraete, Effectiveness of admixtures, surface treatments and antimicrobial compounds against biogenic sulfuric acid corrosion of concrete, Cem. Concr. Compos. 31 (2009) 163-170. doi:10.1016/j.cemconcomp.2008.12.004.

[19] C. Moreau, V. Vergès-Belmin, L. Leroux, G. Orial, G. Fronteau, V. Barbin, Water-repellent and biocide treatments: Assessment of the potential combinations, J. Cult. Herit. 9 (2008) 394-400. doi:10.1016/j.culher.2008.02.002.

[20] J.A. Lemire, J.J. Harrison, R.J. Turner, Antimicrobial activity of metals: mechanisms, molecular targets and applications, Nat. Rev. Microbiol. 11 (2013) 371-384. doi:10.1038/nrmicro3028.

[21] H. Qian, X. Peng, X. Han, J. Ren, L. Sun, Z. Fu, Comparison of the toxicity of silver nanoparticles and silver ions on the growth of terrestrial plant model Arabidopsis thaliana, J. Environ. Sci. 25 (2013) 1947-1956. doi:10.1016/S1001-0742(12)60301-5.

[22] N.M. Gómez-Ortíz, W.S. González-Gómez, S.C. De la Rosa-García, G. Oskam, P. Quintana, M. Soria-Castro, S. Gómez-Cornelio, B.O. Ortega-Morales, Antifungal activity of $\mathrm{Ca}[\mathrm{Zn}(\mathrm{OH}) 3] 2 \cdot 2 \mathrm{H} 2 \mathrm{O}$ coatings for the preservation of limestone monuments: An in vitro study, Int. Biodeterior. Biodegrad. 91 (2014) 1-8. doi:10.1016/j.ibiod.2014.02.005.

[23] J. MacMullen, Z. Zhang, H.N. Dhakal, J. Radulovic, A. Karabela, G. Tozzi, S. Hannant, M.A. Alshehri, V. Buhé, C. Herodotou, M. Totomis, N. Bennett, Silver nanoparticulate enhanced aqueous silane/siloxane exterior facade emulsions and their efficacy against algae and cyanobacteria biofouling, Int. Biodeterior. Biodegrad. 93 (2014) 54-62. doi:10.1016/j.ibiod.2014.05.009.

[24] R. Zarzuela, M. Carbú, M.L.A. Gil, J.M. Cantoral, M.J. Mosquera, $\mathrm{CuO} / \mathrm{SiO} 2$ nanocomposites: A multifunctional coating for application on building stone, Mater. Des. (2016). doi:10.1016/j.matdes.2016.11.009.

[25] L. Luvidi, A.M. Mecchi, M. Ferretti, G. Sidoti, Treatments with self-cleaning products for the maintenance and conservation of stone surfaces, Int. J. Conserv. Sci. 7 (2016) 311-322.

[26] D. Pinna, B. Salvadori, M. Galeotti, Monitoring the performance of innovative and traditional biocides mixed with consolidants and water-repellents for the prevention of biological growth on stone, Sci. Total Environ. 423 (2012) 132-141. doi:10.1016/j.scitotenv.2012.02.012.

[27] D. Colangiuli, A. Calia, N. Bianco, Novel multifunctional coatings with photocatalytic and hydrophobic properties for the preservation of the stone building heritage, Constr. Build. Mater. 93 (2015) 189-196. doi:10.1016/j.conbuildmat.2015.05.100.

[28] S.A. Ruffolo, M. Ricca, A. Macchia, M.F. La Russa, Antifouling coatings for underwater archaeological stone materials, Prog. Org. Coat. 104 (2017) 64-71. doi:10.1016/j.porgcoat.2016.12.004.

[29] O.V. Rúnarsson, J. Holappa, T. Nevalainen, M. Hjálmarsdóttir, T. Järvinen, T. Loftsson, J.M. Einarsson, S. Jónsdóttir, M. Valdimarsdóttir, M. Másson, Antibacterial activity of methylated chitosan and chitooligomer derivatives: Synthesis and structure activity relationships, Eur. Polym. J. 43 (2007) 2660-2671. doi:10.1016/j.eurpolymj.2007.03.046. 
[30] D. Raafat, H.-G. Sahl, Chitosan and its antimicrobial potential - a critical literature survey, Microb. Biotechnol. 2 (2009) 186-201. doi:10.1111/j.1751-7915.2008.00080.x.

[31] S. Eyssautier-Chuine, N. Vaillant-Gaveau, M. Gommeaux, C. Thomachot-Schneider, J. Pleck, G. Fronteau, Efficacy of different chemical mixtures against green algal growth on limestone: A case study with Chlorella vulgaris, Int. Biodeterior. Biodegrad. 103 (2015) 59-68. doi:10.1016/j.ibiod.2015.02.021.

[32] C. Thomachot-Schneider, M. Gommeaux, G. Fronteau, C.T. Oguchi, S. Eyssautier, B. Kartheuser, A comparison of the properties and salt weathering susceptibility of natural and reconstituted stones of the Orval Abbey (Belgium), Environ. Earth Sci. 63 (2011) 1447-1461. doi:10.1007/s12665-010-0743-8.

[33] G. Fronteau, Comportements télogénétiques des principaux calcaires de Champagne-Ardenne : en relation avec leur facies de dépôt et leur sequençage diagénétique, Ph.D thesis, University of Rheims Champagne-Ardenne, 2000. https://www.theses.fr/2000REIMS011 (accessed February 19, 2018).

[34] S. Eyssautier-Chuine, M. Gommeaux, C. Moreau, C. Thomachot-Schneider, G. Fronteau, J. Pleck, B. Kartheuser, Assessment of new protective treatments for porous limestone combining waterrepellency and anti-colonization properties, Q. J. Eng. Geol. Hydrogeol. 47 (2014) 177-187. doi:10.1144/qjegh2013-026.

[35] G. Fronteau, V. Barbin, A. Pascal, Impact du faciès sédimento-diagénétique sur l'altération en œuvre d'un géomatériau calcaire, Comptes Rendus Académie Sci. - Ser. IIA - Earth Planet. Sci. 328 (1999) 671-677. doi:10.1016/S1251-8050(99)80176-1.

[36] O. Guillitte, Bioreceptivity: a new concept for building ecology studies, Sci. Total Environ. 167 (1995) 215-220. doi:10.1016/0048-9697(95)04582-L.

[37] M. Alvarez de Buergo BallesterBallester, R.F. González, Characterizing the construction materials of a historic building and evaluating possible preservation treatments for restoration purposes, Geol. Soc. Lond. Spec. Publ. 205 (2002) 241-254. doi:10.1144/GSL.SP.2002.205.01.18.

[38] M. Alvarez de Buergo Ballester, R. Fort, M. Gomez-Heras, Contributions of Scanning Electron Microscopy to the Assessment of the Effectiveness of Stone Conservation Treatments, Scanning. 26 (2004) 41-47.

[39] D. Kronlund, M. Lindén, J.-H. Smått, A sprayable protective coating for marble with waterrepellent and anti-graffiti properties, Prog. Org. Coat. 101 (2016) 359-366. doi:10.1016/j.porgcoat.2016.07.022.

[40] B. Sena da Fonseca, A.P. Ferreira Pinto, S. Piçarra, M.F. Montemor, Artificial aging route for assessing the potential efficacy of consolidation treatments applied to porous carbonate stones, Mater. Des. 120 (2017) 10-21. doi:10.1016/j.matdes.2017.02.001.

[41] W. Sajomsang, P. Gonil, S. Saesoo, Synthesis and antibacterial activity of methylated N-(4-N,Ndimethylaminocinnamyl) chitosan chloride, Eur. Polym. J. 45 (2009) 2319-2328. doi:10.1016/j.eurpolymj.2009.05.009.

[42] N.L. Loseva, A.J. Alyabyev, L.K. Gordon, I.N. Andreyeva, O.P. Kolesnikov, A.A. Ponomareva, R.B. Kemp, The effect of AgNO3 on the bioenergetic processes and the ultrastructure of Chlorella and Dunaliella cells exposed to different saline conditions, Thermochim. Acta. 458 (2007) 71-76. doi:10.1016/j.tca.2007.02.015.

[43] A. Oukarroum, S. Bras, F. Perreault, R. Popovic, Inhibitory effects of silver nanoparticles in two green algae, Chlorella vulgaris and Dunaliella tertiolecta, Ecotoxicol. Environ. Saf. 78 (2012) 80 85. doi:10.1016/j.ecoenv.2011.11.012.

[44] H.-S. Jiang, M. Li, F.-Y. Chang, W. Li, L.-Y. Yin, Physiological analysis of silver nanoparticles and AgNO3 toxicity to Spirodela polyrhiza, Environ. Toxicol. Chem. 31 (2012) 1880-1886. doi:10.1002/etc. 1899 .

[45] T. Künniger, A.C. Gerecke, A. Ulrich, A. Huch, R. Vonbank, M. Heeb, A. Wichser, R. Haag, P. Kunz, M. Faller, Release and environmental impact of silver nanoparticles and conventional organic biocides from coated wooden façades, Environ. Pollut. 184 (2014) 464-471. doi:10.1016/j.envpol.2013.09.030. 
[46] C.-M. Zhao, W.-X. Wang, Comparison of acute and chronic toxicity of silver nanoparticles and silver nitrate to Daphnia magna, Environ. Toxicol. Chem. 30 (2011) 885-892. doi:10.1002/etc. 451.

[47] European Committee for Standardization, NF EN ISO 11664-4 - Colorimétrie - Partie 4 : espace chromatique L*a*b* CIE 1976, (2011). https://www.boutique.afnor.org/norme/nf-en-iso-116644/colorimetrie-partie-4-espace-chromatique-lab-cie-1976/article/695975/fa161153 (accessed June 30, 2017).

[48] U. Schreiber, W. Bilger, C. Neubauer, Chlorophyll fluorescence as a nonintrusive indicator for rapid assessment of In Vivo Photosynthesis, in: Ecophysiol. Photosynth. Ecol. Stud., SpringerVerlag, Schulze E.-D., Caldwell M.M., Berlin Heidelberg, 1994: pp. 49-70.

[49] B. Genty, J.-M. Briantais, N.R. Baker, The relationship between the quantum yield of photosynthetic electron transport and quenching of chlorophyll fluorescence, Biochim. Biophys. Acta BBA - Gen. Subj. 990 (1989) 87-92. doi:10.1016/S0304-4165(89)80016-9.

[50] O. van Kooten, J.F.H. Snel, The use of chlorophyll fluorescence nomenclature in plant stress physiology, Photosynth. Res. 25 (1990) 147-150. doi:10.1007/BF00033156.

[51] European Commitee for Standardization NF EN 15803, Conservation of cultural property. Test methods. Determination of water vapour permeability, (2010).

[52] European Commitee for Standardization EN 16581, Conservation of Cultural Heritage - Surface protection for porous inorganic materials - Laboratory test methods for the evaluation of the performance of water repellent products, (2015).

[53] European Committee for Standardization EN 15802, Conservation of Cultural Heritage - Test methods- determination of static contact angle., (2010).

[54] R Core Team, R: A language and environment for statistical computing. R Foundation for Statistical Computing, Vienna, Austria., 2014. http://www.R-project.org/.

[55] H. Wickham, ggplot2: Elegant Graphics for Data Analysis., Springer-Verlag, New York, 2009. http://ggplot2.tidyverse.org, https://github.com/tidyverse/ggplot2.

[56] H. Bengtsson, R.utils: Various Programming Utilities. R package version 2.5.0., 2016. https://CRAN.R-project.org/package=R.utils.

[57] S. Højsgaard, U. Halekoh, doBy: Groupwise Statistics, LSmeans, Linear Contrasts, Utilities. R package version 4.5-15., 2016. https://CRAN.R-project.org/package=doBy.

[58] H. Wickham, readxl: Read Excel Files. R package version 0.1.1., 2016. https://CRAN.Rproject.org/package=readxl.

[59] P. Johnson, devEMF: EMF Graphics Output Device. R package version 2.0., 2015. https://CRAN.R-project.org/package=devEMF.

[60] H.R. Sasse, R. Snethlage, Methods for evaluation of stone conservation treatments., in: Rep. Dahl. Workshop Sav. Our Herit. Conserv. Hist. Stone Struct., Baer, N.S., Snethlage, R., Berlin, 1996: pp. 223-243.

[61] C. Moreau, L. Leroux, V. Vergès-Belmin, G. Fronteau, V. Barbin, Which factors influence most the durability of water repellent treatments: stone properties, climate or atmospheric pollution?, in: Aedificatio Publisher, De Clercq H. and Charola A. E., Brussels, Belgium, 2008: pp. 129-142.

[62] W. De Muynck, A.M. Ramirez, N. De Belie, W. Verstraete, Evaluation of strategies to prevent algal fouling on white architectural and cellular concrete, Int. Biodeterior. Biodegrad. 63 (2009) 679-689. doi:10.1016/j.ibiod.2009.04.007.

[63] N.A. Cutler, H.A. Viles, S. Ahmad, S. McCabe, B.J. Smith, Algal "greening" and the conservation of stone heritage structures, Sci. Total Environ. 442 (2013) 152-164. doi:10.1016/j.scitotenv.2012.10.050.

[64] F. Borderie, N. Tête, D. Cailhol, L. Alaoui-Sehmer, F. Bousta, D. Rieffel, L. Aleya, B. AlaouiSossé, Factors driving epilithic algal colonization in show caves and new insights into combating biofilm development with UV-C treatments, Sci. Total Environ. 484 (2014) 43-52. doi:10.1016/j.scitotenv.2014.03.043.

[65] D. Li, F. Xu, L. Shao, M. Wan, Effect of the addition of 3-glycidoxypropyltrimethoxysilane to tetraethoxyorthosilicate-based stone protective coating using n-octylamine as a catalyst, Bull. Mater. Sci. 38 (2015) 49-55. 
[66] W. Rose, Aspects des processus de mouillage dans les solides poreux, Rev. L'Institut Fr. Pet. 18 (1963) 1571-1590.

[67] D.A. De Vries, A.J. Kruger, On the value of the diffusion coefficient of water vapour in air, in: Phénom. Transp. Dans Milieux Poreux Ou Colloïdaux, CNRS, 1967: pp. 61-72.

[68] D. Quenard, H. Sallee, Water vapour adsorption and transfer in cement-based materials: a network simulation, Mater. Struct. 25 (1992) 515-522. doi:10.1007/BF02472447.

[69] B. Tournier, D. Jeannette, C. Destrigneville, Stone drying: An approach of the effective evaporating surface area, in: V. Fassina (Ed.), Proc. 9th Int. Congr. Deterioration Conserv. Stone, Elsevier Science B.V., Amsterdam, 2000: pp. 629-635. doi:10.1016/B978-044450517-0/501495.

[70] C. Esposito Corcione, R. Manno, M. Frigione, Sunlight curable boehmite/siloxane-modified methacrylic nano-composites: An innovative solution for the protection of carbonate stones, Prog. Org. Coat. 97 (2016) 222-232. doi:10.1016/j.porgcoat.2016.04.037.

[71] B. Simionescu, M. Aflori, M. Olaru, Protective coatings based on silsesquioxane nanocomposite films for building limestones, Constr. Build. Mater. 23 (2009) 3426-3430. doi:10.1016/j.conbuildmat.2009.06.032.

[72] R. Striani, C. Esposito Corcione, G. Dell'Anna Muia, M. Frigione, Durability of a sunlight-curable organic-inorganic hybrid protective coating for porous stones in natural and artificial weathering conditions, Prog. Org. Coat. 101 (2016) 1-14. doi:10.1016/j.porgcoat.2016.07.018.

\section{List of tables and figures:}

Table 1

Coating names with the test used for their efficacy, their function, the applied product quantity, the equivalent dry weight and the concentration of components (Tegosivin ${ }^{\circledR}$ HE 328 concentration is not mentioned as it is $97 \mathrm{~g} / \mathrm{L}$ in all coatings).

\section{Table 2}

Mercury intrusion porosimetry for control, TCAg-7 and TCAg-14 coated stones before and after the accelerated ageing test: percentage of $\mathrm{Hg}$ porosity $(\%)$ and $\mathrm{Hg}$ intrusion $\left(\mathrm{mL} \cdot \mathrm{g}^{-1}\right)$ for the four classes of pore access radii.

\section{Table 3}

Concentration of Silicon in mass fraction (wt (\%)) on the surface of calcitic grains and on compact films on stones coated by TCAg-7, TCAg-14, T-7 and T-14.

\section{Table 4}

Reduction of water vapour permeability $\left(\delta_{\mathrm{p} \text { red }}\right)$ and transmission degree of water vapour $(\mathrm{V})$.

\section{Figure 1.}

Global colour variation $\Delta \mathrm{E}^{*}$ ab represents the colour difference between the stone surface before the application of coatings and after in the CIELAB colour space. The threshold of the visual colour variation for the Dom stone is marked by the dotted line at $\Delta \mathrm{E}^{*}{ }_{\mathrm{ab}}=4$ (a). $\Delta \mathrm{h}^{*}{ }_{\mathrm{ab}}$ and $\Delta \mathrm{L}^{*}$ correspond respectively to the variation of the hue and of the lightness of the stone surface before and after the application of coatings (b). See supplementary Tables S1-S2 for means and standard deviations.

\section{Figure 2.}

Mean of $\Delta \mathrm{a}^{*}$ of triplicates calculated from measurements before incubation and after 1,2, 3 and 4 weeks of incubation (a). Evolution of Chl $a$ fluorescence parameters of PSII ( $\phi_{\text {PSII }}$, the effective quantum yield) in Chlorella vulgaris in triplicates of control and coated stones after 1, 2, 3 and 4 weeks of incubation (b), $\mathrm{q}_{\mathrm{P}}$ (the photo-chemical quenching) (c), $\mathrm{q}_{\mathrm{N}}$ (the non photo-chemical quenching that is the heat dissipation) (d). See supplementary Tables S3-S6 for means and standard deviations. 
Figure 3.

Fluorescence imaging of the dynamic evolution of chlorella vulgaris inoculated in control and coated stones. Samples were dark-adapted for 30 minutes and submitted to saturation pulse. A photo of photosynthetic efficiency $\left(\mathrm{F}_{\mathrm{v}} / \mathrm{F}_{\mathrm{m}}\right)$ was captured every test week. The false colour code ranges from black (0.000) to pink (1.000). See supplementary Table S7 for means and standard deviations.

\section{Figure 4.}

Incremental mercury intrusion in relation to the pore size. Comparison of the pore access radii distribution of: the fresh stone (control) and the TCAg-7 and TCAg-14 coated stones before the accelerated ageing (a), the control before and after the accelerated ageing (b), the TCAg-7 and TCAg14 coated stones after the accelerated ageing (c).

\section{Figure 5.}

SEM images and EDS analysis of Dom stone. Natural uncoated stone made of calcitic grains (high Ca peaks) (a). Stone coated with TCAg-7, the film being only identified thanks to a small Si peak on calcitic grains (b). The same coated stone with the coating flooding calcitic grains as a glazing showed by a high Si peak (c). Stone coated with T-7, EDS analysis showing a small peak of Si on stone grains and a higher peak on a glazing $(d)$.

\section{Figure 6.}

SEM images of coated stone. Cracking of the compact film in TCAg-7 after the ageing test (a). Remaining glazing of T-7 on the stone surface (b).

\section{Figure 7.}

Stone colour variation in control and coated stones before the accelerated ageing test and after 42, 84, 126 and 168 cycles. Evolution of the global colour variation $\Delta \mathrm{E}^{*}{ }_{\mathrm{ab}}$ (a). Evolution of $\Delta \mathrm{h}^{*}{ }_{\mathrm{ab}}$ versus $\Delta \mathrm{L}^{*}$ (b). See supplementary Tables S8-10 for means and standard deviations.

\section{Figure 8.}

Evolution of contact angles $(\theta)$ before the accelerated ageing test and after 42, 84, 126 and 168 cycles for every coated stone. See supplementary Table S11 for means and standard deviations. 